\title{
Spatial and temporal distribution of Gymnorhamphichthys rondoni (Gymnotiformes: Rhamphichthyidae) in a long-term study of an Amazonian terra firme stream, Leticia - Colombia
}

\author{
Carolina Escamilla-Pinilla ${ }^{1}$, José Iván Mojica² and Jorge Molina ${ }^{1}$
}

Weakly electric fishes continually emit electric organ discharges (EOD) as a means of communication and localization of objects in their surroundings. Depending on water conductivity, the amplitude of the electric field generated is known to increase with decreases in electrical conductivity of the water. In Amazonian terra firme streams, water conductivity is extremely low and fluctuates constantly due to local and regional rains. In this context, the space between freely moving weakly electric fishes may be expected to decrease, on average, with an increase in water conductivity. To test this hypothesis, we recorded the positions at rest of the sand-dwelling fish Gymnorhamphichthys rondoni in a terra firme stream for several days in alternating months, over two years. Based on daily nearest neighbor distances among individual fish in a grid, we found a uniform temporal distribution pattern (which was not affected by water conductivity) indicative of site fidelity. Here we highlight the role of other factors that could influence resting site fidelity.

Keywords: Electrocommunication range, Nearest neighbor distance, Sand-dwelling, Water conductivity, Weakly electric fish.

Los peces eléctricos emiten continuamente descargas con su órgano eléctrico (DOE) para comunicarse y localizar objetos a su alrededor. Dependiendo de la conductividad del agua, la amplitud del campo eléctrico generado aumenta con una disminución en la conductividad eléctrica del agua. En los arroyos de terra firme amazónicos, la conductividad eléctrica del agua es extremadamente baja y fluctua constantemente dependiendo de las lluvias locales y regionales. Teniendo esto en cuenta, esperamos que el espacio entre peces eléctricos débiles con libertad de movimiento disminuya, en promedio, de acuerdo al incremento en la conductividad del agua. Para evaluar esta hipótesis, registramos bajo condiciones naturales por varios dias en meses alternos y durante dos años las posiciones en reposo del pez Gymnorhamphichthys rondoni en un arroyo de terra firme. Con los valores de registro diario de la distancia al vecino mas cercano en peces individuales dentro de una grilla, encontramos un patrón de distribución temporal uniforme (que no fue afectado por la conductividad del agua) e indicativo de una fidelidad por los sitios de reposo. Entonces, nosotros resaltamos aquí el posible papel que otros factores pueden estar jugando para entender la fidelidad por sus sitios de reposo.

Palabras clave: Conductividad del agua, Distancia al vecino más cercano, Habitante en la arena, Pez eléctrico débil, Rango de electrocomunicación.

\section{Introduction}

South American gymnotiforms produce self-generated weak electrical signals in the form of stereotyped electric organ discharges (EODs). These are used to communicate agonistic behavior, sexual, and physiological state (Silva et al., 2007), and to locate external objects (Caputi, 2017). EODs are continually emitted by these fish when they are at rest and when they become more active at night. These EOD signals can be easily detected and recorded in their natural habitats using a custom electric fish finder (Crampton et al., 2007), and the pulse rate recorded as mp3 files with an audio recorder.

In Colombia, two Rhamphichthyidae species have been described: Gymnorhamphichthys rondoni (Miranda-Ribeiro, 1920) and Gymnorhamphichthys hypostomus Ellis, 1912 (DoNascimiento et al., 2017), of which only the former is known from small streams in the Leticia region (Mojica et al., 2005; Galvis et al., 2006). Gymnorhamphichthys

\footnotetext{
${ }^{1}$ Centro de Investigación en Microbiología y Parasitología Tropical (CIMPAT), Departamento de Ciencias Biológicas, Facultad de Ciencias, Universidad de los Andes, Bloque A, Carrera 1 No. 18A-12 Bogotá, DC, Colombia. (CEP) c.escamilla@uniandes.edu.co, Dhttps://orcid. org/0000-0002-4696-4409; (JM) jmolina@uniandes.edu.co, ○https://orcid.org/0000-0003-3018-6726 (corresponding author)

${ }^{2}$ Instituto de Ciencias Naturales, Universidad Nacional de Colombia, Carrera 30 No. 45-03 Bogotá, DC, Colombia. jimojicac@unal.edu.co, Dhttps://orcid.org/0000-0002-9179-0962
} 
rondoni grows to $c a .225 \mathrm{~mm}$ long, has a translucent body with dark saddle marks on the dorsum, and does not exhibit external sexual dimorphism (Carvalho, 2013). This species has a long tube-like snout with a small mouth lacking teeth. It feeds on aquatic invertebrates via grasping suction (Marrero, Winemiller, 1993; Ramirez et al., 2015). During the day $G$. rondoni burrows itself into sand on the stream bed to evade predators while emitting electric discharges at a rate of ca. $15 \mathrm{~Hz}$ (Crampton, Albert, 2006). After dusk, individuals emerge from their resting sites to forage (Zuanon et al., 2006) and increase their EOD rate to over $100 \mathrm{~Hz}$ (Crampton, Albert, 2006).

The natural habitat of $G$. rondoni includes shaded areas of terra firme streams with sandy bottoms, and occasionally rivers (Schwassmann, 1976). Terra firme streams are located above the peak flooding of the Amazon River (RuedaDelgado et al., 2006) and are consequently unaffected by the hydrological cycle of the river. Their water levels are instead influenced by local precipitation. During the course of the year, water conductivity decreases as the average water level rises during the rainy season (Mojica et al., 2009). Oligotrophic and shallow terra firme streams in the Amazon basin contain high concentrations of humic and fulvic acids, low salt concentrations, and consequently exhibit both low $\mathrm{pH}$ and low electrical conductivity (Lobón-Cerviá et al., 2012; Mojica et al., 2014).

In some gymnotiforms, dissolved oxygen in the water has been known to affect the distribution patterns, movements, and gill morphology of fish in the wild (Crampton, 1998; Crampton et al., 2008). In other fish species there is evidence of site fidelity and clustering behavior due to habitat heterogeneity (Silvano et al., 2000; Rodriguez, 2002; Crook, 2004). In weakly electric fish, clustered behavior has been observed in the laboratory when presented with available retreat sites (resting sites) of varying structures (Dunlap, Oliveri, 2002). In this way, weakly electric fish prefer choosing resting sites with a particular physical structure, substrate geometry, and physicochemical properties to hide during the daytime (Dunlap, Oliveri, 2002; Albert, Crampton, 2005).

Previous studies in laboratory have shown that water conductivity affects the electrocommunication ranges between conspecifics, decreasing the distance between individuals as water conductivity increases (e.g., Knudsen, 1975; Squire, Moller, 1982) (see review in Crampton, 2019). Nevertheless, the association between water conductivity and the spacing of gymnotiform fish at rest in the wild has never been explored, probably because of the difficulty of working with these fish under natural conditions (Westby, 1988). Therefore, knowing that the nearest neighbor distances among individuals, irrespective of direction, can provide a basic measure of the use of space or potential intraspecific competition (Clark, Evans, 1954), we hypothesized that if weakly electric fish adjust their nearest-neighbor distances based on their perception of their neighbors' electric fields, then inter-fish distances in the natural habitat should be inversely related to water conductivity.
The objective of the present study is to examine the spatial and temporal distribution of $G$. rondoni individuals at their day-time resting sites from a long-term ( $c a$. two year) study carried out in an Amazonian terra firme stream. The psammophilous diurnal behavior of $G$. rondoni facilitates its location without interfering with its distribution pattern when at rest (Zuanon et al., 2006), making it an excellent model for monitoring changes in nearest-neighbor distances in response to environmental changes in the wild.

\section{Material and Methods}

Study Area. The study was carried out in a terra firme stream known as Yahuarcaca located in a protected area (Reserva Tanimboca) at $\mathrm{km} 11$ on the road from Leticia to Tarapacá, Amazonas, Colombia (04²2'S; 6994'W) (Fig. 1). Yahuarcaca is a small first order blackwater stream with high transparency and low density of benthos and drift. The stream has been previously characterized in terms of its mean discharge (460 L.s ${ }^{-1}$ ), water conductivity (9.1-52.6 $\left.\mu \mathrm{S} . \mathrm{cm}^{-1}\right), \mathrm{pH}(4.5-5.6)$, mean temperature $\left(24-27.7^{\circ} \mathrm{C}\right)$, and dissolved oxygen (3.4-8.4 mg.. $\mathrm{L}^{-1}$ ) (Rueda-Delgado et al., 2006; Lobón-Cerviá et al., 2012). This stream has a sandy bottom and is found in forest with a dense canopy. The area has moderate to low human intervention (Mojica et al., 2014).

The sampling site is $91 \mathrm{~m}$ in length. The fish community at this site was previously characterized in a long-term study (Mojica et al., 2014). The water system study depends highly on regional and local precipitation with fluctuating water level (0.4-1.9 m), associated with sporadic local precipitation that occurs mostly from November to May (monthly mean $350 \mathrm{~mm}$ ) followed by a drier season from June to October (monthly mean $220 \mathrm{~mm}$ ). Conductivity declines to its lowest levels during the rainy season, and reaches its highest levels during the dry season (Mojica et al., 2014) (Fig. 2).

Gymnorhamphichthys rondoni in the study area generate EODs of approximately $1 \mathrm{~ms}$ duration comprising four phases (Fig. 3). These resemble those reported by Crampton, Albert (2006).

Spatial distribution of $\boldsymbol{G}$. rondoni and sampling grid. We sampled the spatial distribution of $G$. rondoni, and water conductivity for a maximum of five to six consecutive days for a total of 69 days over two years during each of the following months: June, July, September, and November 2016, January, March, May, July, September, and November 2017, January, April, and May 2018. Of the selected sampling months, five months correspond to low precipitation and eight months to a season of high precipitation. A net grid divided into $1.0 \times 1.0 \mathrm{~m}$ quadrants (Fig. 1) was placed over the stream. This was located about $50 \mathrm{~m}$ downstream from the end of the sampling site, to avoid any kind of human disturbance. The entire grid was handmade with dimensions of $8.0 \mathrm{~m}$ in width by $15.0 \mathrm{~m}$ in length, and a total of 120 quadrants $\left(120 \mathrm{~m}^{2}\right)$. It was securely tied upstream to a bridge (Fig. 1) and along its entire length from the banks. 


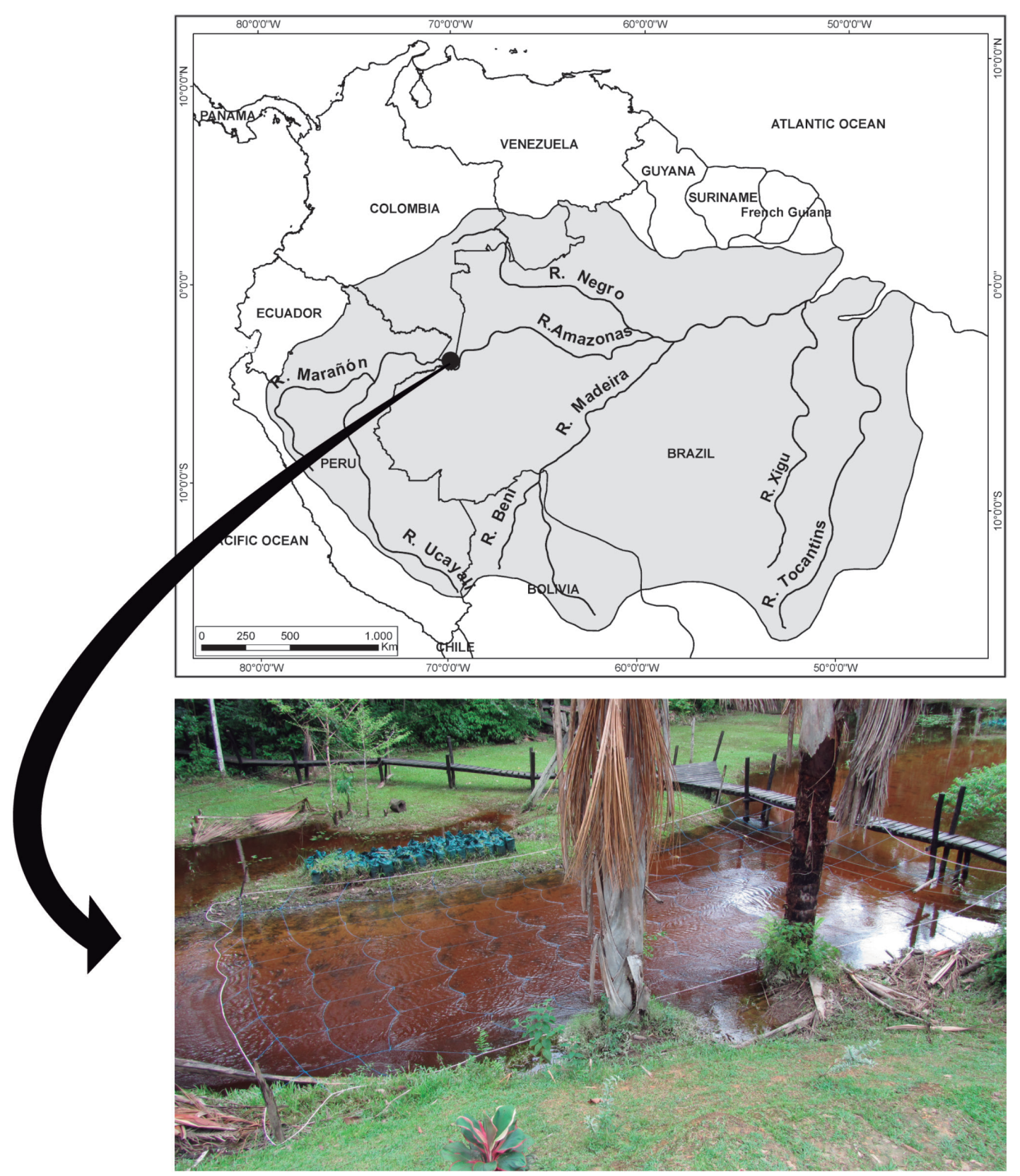

Fig. 1. Geographical position of the sampling site in the Yahuarcaca terra firme stream close to Leticia, Amazonas in Colombia. The picture shows a panoramic view of the sampling site.

The grid was marked horizontally with the letters from A to $\mathrm{H}$, and vertically with the numbers 1 to 15 to facilitate the localization and identification of the individuals found within it. Localization of each fish was carried out by detecting its resting EODs with the aid of a mini-amplifier (Radio Shack, model 2771008), with earphones connected to the line out and a homemade electrode with an inter electrode distance of $25.0 \mathrm{~cm}$ connected to the input. The EODs were recorded as .wav files with a MP3 digital recorder (Transcend, TS8GMP330K) at a sampling rate of $32 \mathrm{kHz}$, and then visualized with Audacity ${ }^{\circledR}$ Software to confirm the species' EOD waveform for each fish (In so doing we confirmed that $100 \%$ of our recordings were of G. rondoni).
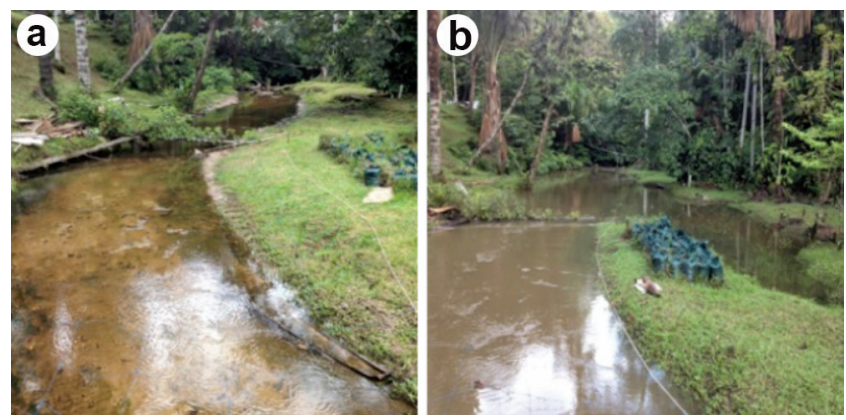

Fig. 2. Sampling site in the Yahuarcaca terra firme stream in Leticia, Amazonas. a. Image during low water levels. b. Image with high water levels after a local rain. 


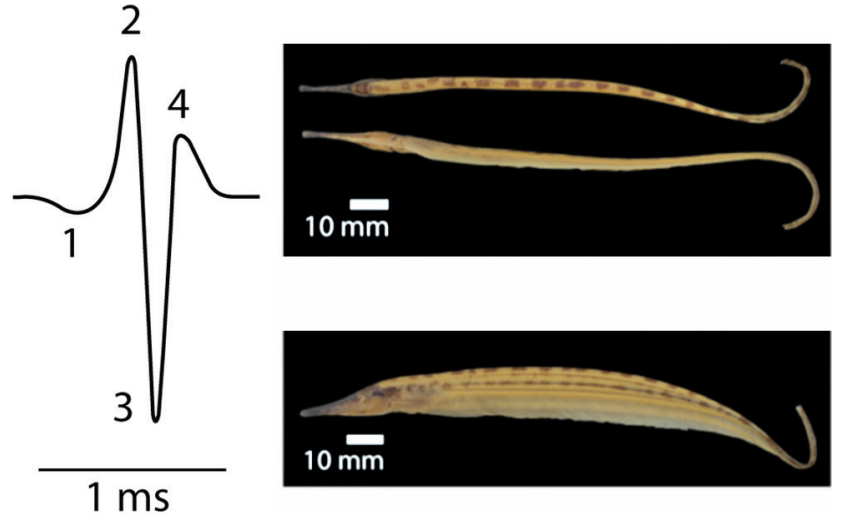

Fig. 3. The EOD pulse in the weakly electric fish Gymnorhamphichthys rondoni. EOD waveform shows four distinctive phases of alternating polarity (Left). Pictures are showing the lateral, dorsal and ventral view of $G$. rondoni ICN-MHN 6169 (Right). (C) Institute of Natural Sciences, Faculty of Sciences, Universidad Nacional de Colombia.

Nearest neighbor distances. The exact location and number of individuals were quantified within the grid on a given sample day at $c a$. 16:00 by marking their position onto a sketch of the grid. This sketch was later scanned and nearestneighbor distances for each individual measured with the Straight Line tool in ImageJ (Rasband, 2019). A total of 1375 nearest neighbor distances were obtained during thirteen months, from 402 individuals located in the grid.

Measurement of water conductivity. Water conductivity was carried out once daily using a multi parameter PCSTestr 35 meter (Eutech) (accuracy $\pm 1 \%$ full scale). To test for a correlation between daily mean water conductivity and the average nearest neighbor distance among individuals on the same sampling day, a linear regression was performed using RWizard (version 4.1).

Ratio of departure from a random distribution. We followed Clark, Evans (1954) for calculating the ratio of departure from randomness (R) for each sampling day. First, we calculated the observed mean distance for each sampling day using all the nearest neighbor distances among individuals divided by the total number of distances taken for that particular sampling day. Second, we calculated the expected mean distance for each sampling day using the density for each particular sampling day. Lastly, we calculated $\mathrm{R}$ for each sampling day by the observed mean nearest neighbor distance over the expected mean nearest neighbor distance. At the end, we obtained a total of 62 values of $\mathrm{R}$, expecting a maximum aggregation distribution with $\mathrm{R}=0$, a random distribution with $\mathrm{R}=1$, and uniform pattern of distribution with $\mathrm{R}>1$ (Clark, Evans, 1954). We also analyzed the relationship between daily mean water conductivity and the daily ratio of departure from a random distribution $(\mathrm{R})$ by using different statistical models (again using RWizard version 4.1). To choose the model that better fits the data the Akaike Information Criterion corrected (AICc) was calculated using Matlab software (here we report the coefficient of determination $\mathrm{R}^{2}$ in lower case to discriminate from our use of $\mathrm{R}$ to represent a random distribution).

Resting distribution of $G$. rondoni within the grid. To determine the resting distribution of $G$. rondoni, we calculated the frequency of occurrence of individuals within a given quadrant in the grid during the study (referred as quadrant "probability") and report this as a heat map. First, the quadrant probability was calculated as follows: all the individuals found throughout all sampling months in a particular quadrant were added up ( 25 was the maximum number of individuals found in a particular quadrant). Then, this value was divided by the total number of days sampled (69) and multiplied by $100 \%$. Thus, the maximum quadrant probability calculated was $36.2 \%$. The heat map was constructed in the following way: First, a scale of colors from red $=0^{\circ}$ to blue $=260^{\circ}$ in the filling color tool (RGB colors) was chosen. Second, we divided the maximum color in the selected scale, $260^{\circ}$, by the maximum quadrant probability, $36.2 \%$, and obtained 7.22. Finally, each calculated quadrant probability was multiplied by, 7.22, and represented with a color from the scale ranging from red to blue.

\section{Results}

Resting distribution of $G$. rondoni and quadrant probability. The average number and range of individuals found each sampling month within the sampling grid in Yahuarcaca terra firme stream are reported in Tab. 1. The number of individuals present in the grid was typically between three and seven.

Tab. 1. Average monthly numbers of Gymnorhamphichthys rondoni individuals found within the sampling grid and average water conductivity recorded in Yahuarcaca terra firme stream in Leticia, Amazonas. $\mathrm{SD}=$ Standard Deviation.

\begin{tabular}{ccc}
\hline $\begin{array}{c}\text { Sampling month } \\
\text { and year }\end{array}$ & $\begin{array}{c}\text { Average number of } \\
\text { individuals (Range) }\end{array}$ & $\begin{array}{c}\text { Average water conductivity } \\
\mu \mathrm{S} . \mathrm{cm}^{-1}(\mathrm{SD})\end{array}$ \\
\hline June 2016 & $3.2(2-4)$ & $16.98(4.00)$ \\
July 2016 & $4.3(3-6)$ & $21.04(8.67)$ \\
September 2016 & $5.3(3-7)$ & $48.72(1.76)$ \\
November 2016 & $2(2)$ & $56.21(1.14)$ \\
January 2017 & $3.5(3-5)$ & $22.23(2.16)$ \\
March 2017 & $6(1-11)$ & $13.14(4.08)$ \\
May 2017 & $7(5-10)$ & $19.77(3.51)$ \\
July 2017 & $13.6(13-15)$ & $57.64(0.48)$ \\
September 2017 & $10(8-12)$ & $37.3(7.24)$ \\
November 2017 & $5.75(4-7)$ & $31.37(1.36)$ \\
January 2018 & $4.5(4-6)$ & $17.14(2.32)$ \\
April 2018 & $7.6(6-9)$ & $28.68(3.67)$ \\
May 2018 & $7.2(6-9)$ & $20.70(2.17)$ \\
\hline
\end{tabular}


Occurrences of G. rondoni in each 1-square-meter are reported in Fig. 4 and summarized in the heatmap in Fig. 5. Quadrants that were exposed during low water months showed a quadrant probability of $0 \%$ in Fig. 5 . All other quadrants with color (probability $>0 \%$ ) matched those sites within the grid that were always inundated. The maximum probability obtained of finding a G. rondoni at rest was
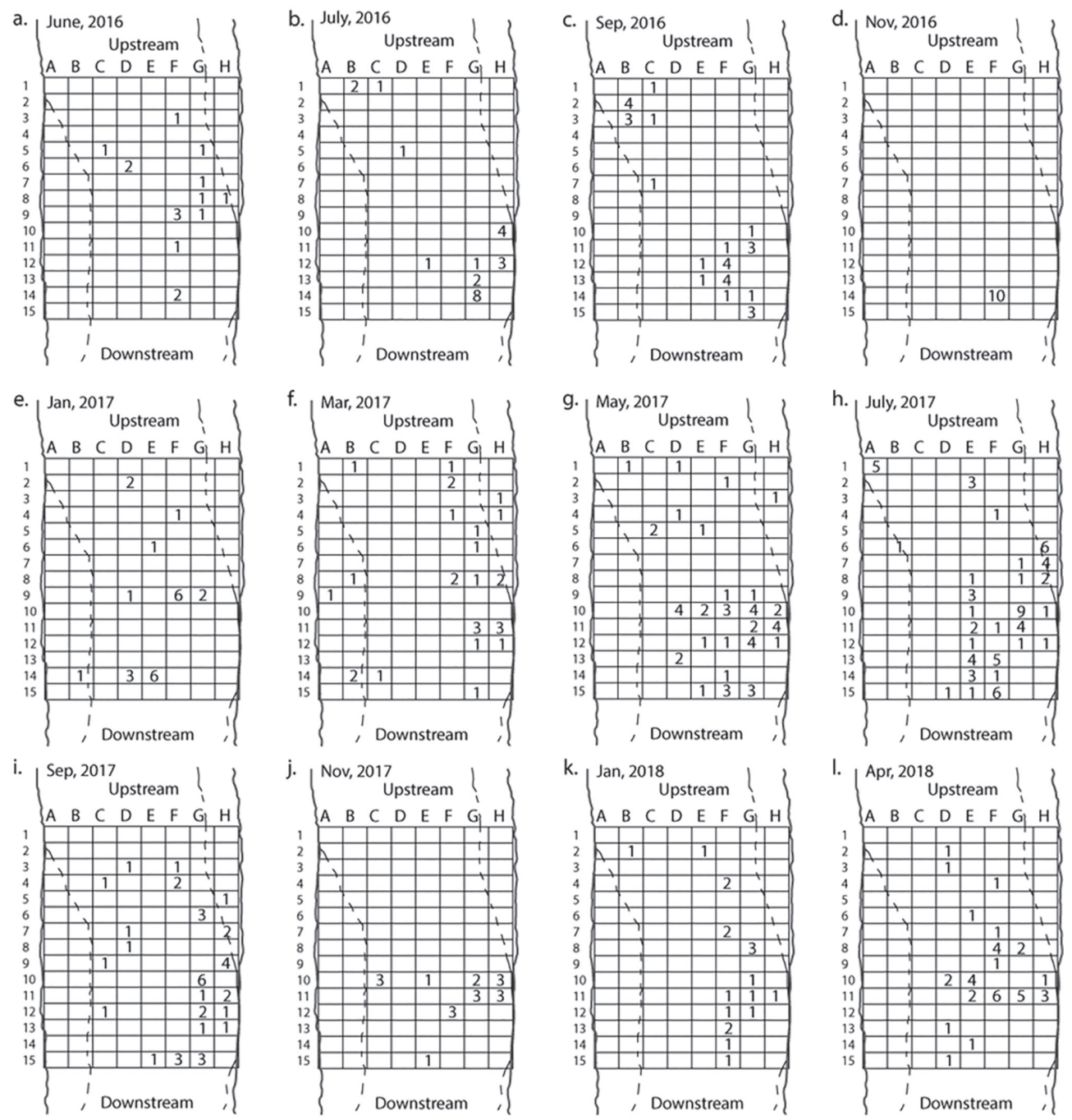
during the day.

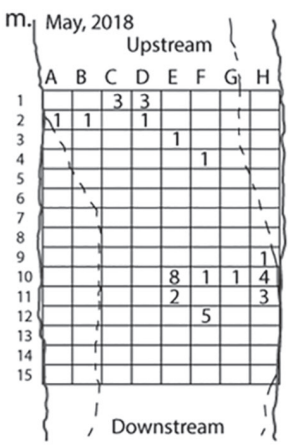

$36.2 \%$ for quadrant G10. In summary, the data presented in Figs. 4-5 indicate that individuals were distributed nonrandomly. Specifically, they chose resting sites that were always inundated and where there was always enough sand at the bottom of the stream for them to burrow into. We noted that fish did not change their position in the sand

Fig. 4. Monthly distribution of Gymnorhamphichthys rondoni within the grid in the Yahuarcaca terra firme stream in Leticia, Amazonas. The continuous line represents the maximum stream width reached during high water months, and the dashed line the minimum stream width reached in low water months. a. to $\mathbf{m}$. Each sketch represents a sampling month and each number represents the total number of $G$. rondoni individuals found during five to six days at each quadrant for that particular month. 


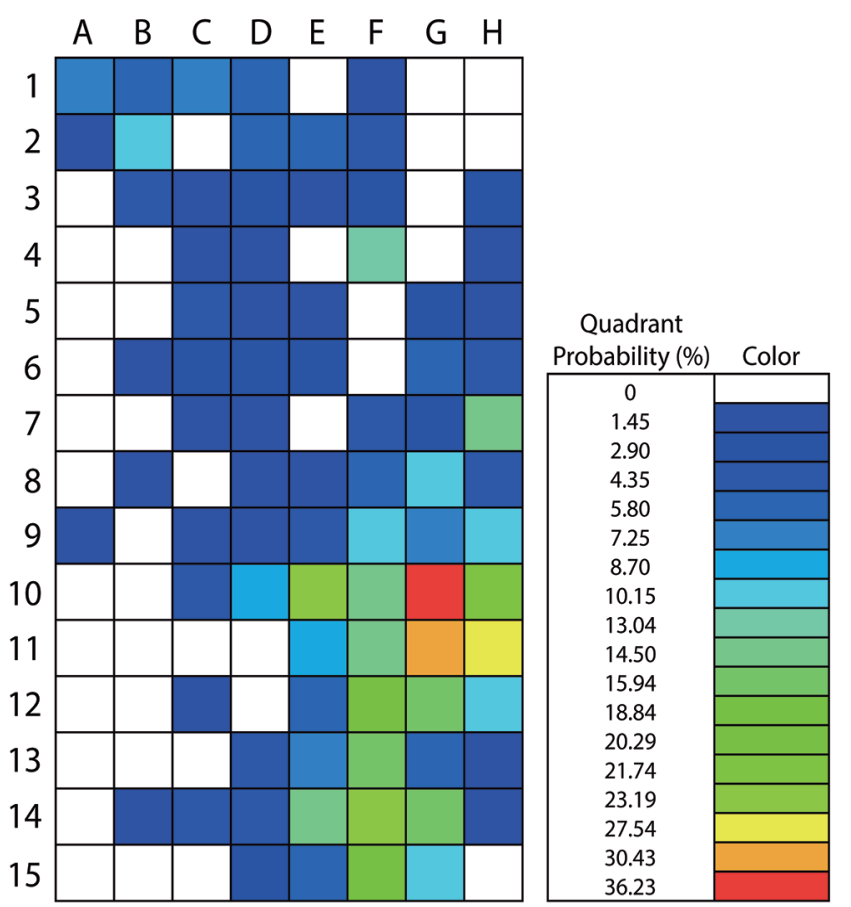

Fig. 5. Heat map showing the probability of finding Gymnorhamphichthys rondoni individuals within any quadrant of the grid located in a terra firme stream in Leticia, Amazonas. White represents zero probability. Dark blue represents the lowest probability for quadrants in which $G$. rondoni rested during the day $(1.45 \%)$ while red represents the highest probability (36.2\%) of finding an individual resting within a given quadrant. Notice that individuals were never found in the white quadrants, which dried out during low water periods.
Water conductivity and distance to nearest neighbor. Water conductivity in the Yahuarcaca stream ranged from 8 to $58 \mu \mathrm{S} . \mathrm{cm}^{-1}$ during the study (Tab. 1). No significant correlation was found between all daily mean nearest neighbor distance and daily water conductivity (linear regression, $n=1375 ; p=0.447 ; r^{2}=0.00042$ ) (Fig. 6a). This suggests that other seasonally varying factors, which were not measured or considered here, may directly influence the distribution of the fish in this study.

Water conductivity and the ratio of departure from a random distribution (R). We found that the exponential and power models fit our data, but with small coefficients of determination $\left(\mathrm{r}^{2}=0.09045 ; \mathrm{F}_{(1,62)}=6.364 ; \mathrm{p}=0.01414\right.$ and $\mathrm{r}^{2}=0.07133 ; \mathrm{F}_{(1,62)}=4.916 ; \mathrm{p}=0.03017$, respectively) (Figs. $6 \mathrm{~b}, \mathrm{c})$. Other models showed even weaker relationships (cubic model $\mathrm{r}^{2}=0.02083, \mathrm{p}=0.7254$; linear model $\mathrm{r}^{2}=$ $0.003024, \mathrm{p}=0.661$; logarithmic model $\mathrm{r}^{2}=0.004221$, $\mathrm{p}=0.6043$; quadratic model $\mathrm{r}^{2}=0.003027, \mathrm{p}=0.9089$; S-curve model $\mathrm{r}^{2}=0.05138, \mathrm{p}=0.06721$; and inverse model $\mathrm{r}^{2}=0.007503, \mathrm{p}=0.4892$ ). The AICc calculated for all models showed only the exponential model close to zero $(\mathrm{AICc}=1.3)$; a group of several models with values higher than 3 (power model $=3.54$; linear model $=3.62$; logarithmic model $=3.69$; inverse model $=4.21$; quadratic model $=8.23$; and S-curve model $=8.31$, and only one model with a value higher than 10 (cubic model $=10.47$ ). Gymnorhamphichthys rondoni individuals within this terra firme stream showed a uniform pattern of distribution at rest (with $\mathrm{R}$ values higher than 1 in both the exponential and power-function models) despite the observed variation in water conductivity (Fig. 6b).
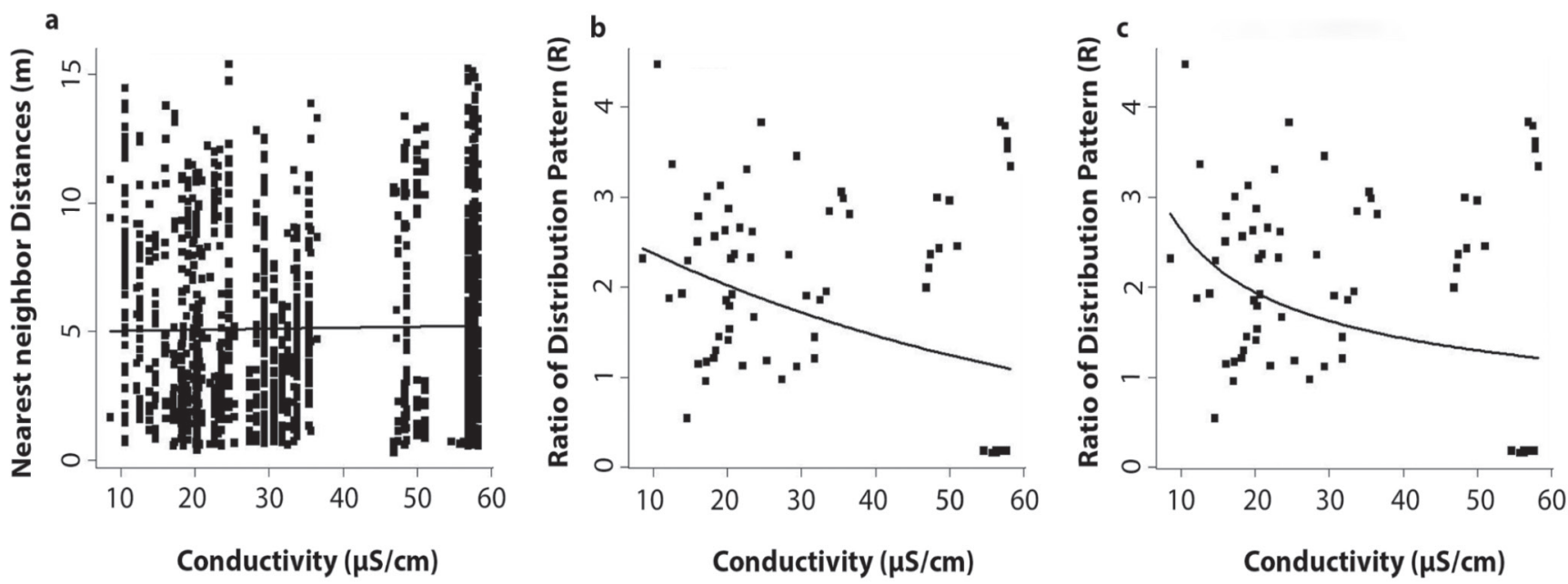

Fig. 6. Water conductivity and its effects on distance to nearest neighbors and the daily ratio of departure from a random distribution (R). a. The nearest neighbor distance between all individuals of Gymnorhamphichthys rondoni found within the grid for all sampling days during all thirteen months (linear regression, $n=1375 ; \mathrm{p}=0.45 ; \mathrm{r}^{2}=$ $0.0004)$. The daily ratio of departure from a random distribution $(\mathrm{R})$ within the grid for all sampling days during all thirteen months for b. Exponential Model $\left(\mathrm{r}^{2}=0.09 ; \mathrm{F}_{(1,62)}=6.4 ; \mathrm{p}=0.014\right)$ and $\mathbf{c}$. Power Model $\left(\mathrm{r}^{2}=0.07 ; \mathrm{F}_{(1,62)}=\right.$ $4.9 ; \mathrm{p}=0.03)$. 


\section{Discussion}

Our two-year field survey of a stable population of freely moving Gymnorhamphichthys rondoni reported a uniform temporal distribution pattern, with water conductivity playing no role in its nearest-neighbor distance. We also observed a clear spatial preference of $G$. rondoni for specific resting sites during the day. We noted that highly preferred sites within the sampling grid match corresponded to areas of the stream bed that never dry up, even during the low water months. We usually found three to seven individuals of $G$. rondoni per sampling month within the grid. Sometimes we detected a clumped distribution throughout the sampling months despite the temporal fluctuations in water conductivity.

Our study suggests that, at rest, G. rondoni individuals tolerate being close to one another during their period of nocturnal rest, despite the low density of individuals and the fluctuation observed in water conductivity. Other studies have also shown non-random resting site selection in other weakly electric fish. For example, Dunlap, Oliveri (2002) demonstrated under laboratory conditions that in social groups of gymnotiform species, males prefer to be alone, while females cluster closer together at the same site. Also, Moller (1976, 2002) shows that Mormyridae species tend to aggregate during the day.

Nonetheless, a major limitation of our study is that we quantified distances among Gymnorhamphichthys only during their period of rest. Because inter-individual spacing at night, when individuals are active, is expected to represent a better measure of territorial sizes, future studies should focus on quantifying active space at night.

Also, in our study, in order to avoid any kind of unnatural disturbance, we avoided capturing G. rondoni individuals during the entire study. Future studies at the sampling site and capturing individuals for sexing will make it clear if sex-specific or age-specific variation in microhabitat occupancy may explain the occasional clumped spatial distribution reported here for $G$. rondoni. For instance, sexually interacting pairs of $G$. rondoni may occupy nearby resting sites during periods of courtship and breeding.

Several laboratory-based studies have explored the relation between water conductivity and the electrocommunication range or distance between weakly electric fish. Squire, Moller (1982) find that increasing water conductivity from $52 \mu \mathrm{S} . \mathrm{cm}^{-1}$ to $678 \mu \mathrm{S} . \mathrm{cm}^{-1}$ decreases the amplitude of the electric discharge and the distance of discharge cessation between Mormyridae individuals. Thus, an increase in water conductivity affects their electrocommunication range reducing its range as well as the distance between individuals. Similarly, Knudsen (1975) found that increasing water conductivity from $\sim 100 \mu \mathrm{S} . \mathrm{cm}^{-1}$ to $600 \mu{\mathrm{S} . \mathrm{cm}^{-1}}^{-1}$ decreases the electrocommunication distance, or the electric fields over distance, between gymnotiform individuals. Other studies indicate that mormyrids can adjust the amplitude of their EODs across a range of water conductivities (Kramer, Kuhn, 1993; Baier, 2008). However, for a gymnotiform, Thomas et al. (1997) reported that the electrical behavior of Apteronotus albifrons was not affected by a 30-minute interval increase in water conductivity within the range from $54 \mu \mathrm{S} . \mathrm{cm}^{-1}$ to $484 \mu \mathrm{S} . \mathrm{cm}^{-1}$.

Our study of $G$. rondoni represents the first to test the hypothesis that active space between wild electric fish may be influenced by conductivity, as predicted by laboratory observations. However, no effect was found between conductivity and spacing in the sand-dwelling G. rondoni. Our study did not evaluate changes in EOD amplitude in response to seasonal conductivity variations.

Several biotic or abiotic variables that we did not quantify in this study, including details of the substrate, body sizes, and reproductive status may influence the spatiotemporal patterns of resting site selection we observed in G. rondoni individuals. For example, some studies have also shown low displacement, restricted movement, strong site fidelity, and occupation of restricted home-ranges in response to environmental changes, predation pressure, antagonistic behavior, and food availability in different riverine and stream fish species (Silvano et al., 2000; Rodriguez, 2002; Crook, 2004). Future studies of the distributions of $G$. rondoni, preferably during their period of nocturnal activity, could focus on such patterns. Likewise, it may be rewarding to explore variation in the microhabitat occupancy and inter-individual spacing related to food availability and dissolved oxygen concentrations.

In conclusion, the sand-burrowing electric fish $G$. rondoni exhibits a uniform spatial distribution pattern in daily resting sites, with resting site preference depending largely on whether a given position was represented by sufficient sand, and whether the site is exposed during periods of low water. Our results suggest that it is unlikely that water conductivity alone is an important factor in shaping nearest-neighbor distances between resting sites among G. rondoni individuals. However, further studies focused on the average spacing among nocturnally active individuals may be more informative of the effects of conductivity on active space.

\section{Acknowledgments}

We thank Reserva Tanimboca for allowing us to carry out the study in the Yahuarcaca terra firme stream. This project was funded by the Faculty of Sciences at Universidad de los Andes, Bogotá, Colombia with a 'Proyecto Semilla' research grant to Carolina Escamilla and also an additional research grant to Jorge Molina. We also thank two anonymous reviewers and the Associate Editor, William G.R. Crampton, for their valuable comments and suggestions to improve this manuscript. We are grateful to Mario Iván Ortiz Yanine for all support with the AIC calculations. Finally, we thank Henry Agudelo-Zamora for taking the pictures of the G. rondoni individual preserved at Instituto de Ciencias Naturales, Universidad Nacional de Colombia. 


\section{References}

Albert JS, Crampton WGR. Diversity and phylogeny of Neotropical electric fishes. In: Bullock TH, Hopkins CD, Popper AN, Fay RR, editors. Electroreception. New York: Springer; 2005. p.360-409.

Baier B. Effect of conductivity changes on the stability of electric signal waveforms in dwarf stonebashers (Mormyridae; Pollimyrus castelnaui, P. marianne). J Comp Physiol A. 2008; 194(10):915-19. https://doi.org/10.1007/s00359-0080360-0

Caputi AA. The bioinspiring potential of weakly electric fish. Bioinspir Biomim. 2017; 12(2):025004. https://doi. org/10.1088/1748-3190/12/2/025004

Carvalho TP. Systematics and evolution of the toothless knifefishes Rhamphichthyoidea Mago-Leccia (Actinopterygii: Gymnotiformes) diversification in South American freshwaters. [PhD Thesis]. Louisiana, United States: University of Louisiana at Lafayette; 2013. https:// pqdtopen.proquest.com/doc/1524021066.html?FMT=ABS

Clark PJ, Evans FC. Distance to nearest neighbor as a measure of spatial relationships in populations. Ecology. 1954; 35(4):445-53. http://dx.doi.org/10.2307/1931034

Crampton WGR. Effects of anoxia on the distribution, respiratory strategies and electric signal diversity of gymnotiform fishes. J Fish Biol. 1998; 53 (Suppl. A):307-30. https://doi. org/10.1111/j.1095-8649.1998.tb01034.x

Crampton WGR. Electroreception, electrogenesis and electric signal evolution. J Fish Biol. 2019; 95(1):92-134. https:// doi.org/10.1111/jfb.13922

Crampton WGR, Albert JA. Evolution of electric signal diversity in gymnotiform fishes. In: Ladich F, Collin SP, Moller P, Kapoor BG, editors. Communication in fishes. Enfield, NH: Science Publishers; 2006. p.647-731.

Crampton WGR, Chapman LJ, Bell J. Interspecific variation in gill size is correlated to ambient dissolved oxygen in the Amazonian electric fish Brachyhypopomus (Gymnotiformes: Hypopomidae). Environ Biol Fish. 2008; 83(2):223-35. https://doi.org/10.1007/s10641-007-9325-3

Crampton WGR, Wells JK, Smyth C, Walz SA. Design and construction of an electric fish finder. Neotrop Ichthyol. 2007; 5(3):425-28. http://dx.doi.org/10.1590/S167962252007000300022

Crook DA. Is the home range concept compatible with the movements of two species of lowland river fish? J Anim Ecol. 2004; 73(2):353-66. https://doi.org/10.1111/j.00218790.2004.00802.x

DoNascimiento C, Herrera-Collazos EE, Herrera-R GA, OrtegaLara A, Villa-Navarro FA, Oviedo JSU, Maldonado-Ocampo JA. Checklist of the freshwater fishes of Colombia: a Darwin Core alternative to the updating problem. ZooKeys. 2017; 708:25-138. https://doi.org/10.3897/zookeys.708.13897

Dunlap K, Oliveri L. Retreat site selection and social organization in captive electric fish, Apteronotus leptorhynchus. J Comp Physiol A. 2002; 188(6):469-77. https://doi.org/10.1007/ s00359-002-0319-5
Galvis G, Mojica JI, Duque SR, Castellanos C, Sánchez-Duarte P, Arce M, Gutiérrez A, Jiménez LF, Santos M, VejaranoRivadeneira S, Arbeláez F, Prieto E, Leiva M. Peces del medio Amazonas. Región de Leticia. Bogotá: Editorial Panamericana, Formas e Impresos; 2006.

Knudsen EI. Spatial aspects of the electric fields generated by weakly electric fish. J Comp Physiol A. 1975; 99(2):103-18. https://doi.org/10.1007/BF00618178

Kramer B, Kuhn B. Electric signaling and impedance matching in a variable environment. Naturwissenschaften. 1993; 80(1):4346. https://doi.org/10.1007/BF01139760

Lobón-Cerviá J, Rezende CF, Castellanos CPJ. High species diversity and low density typify drift and benthos composition in Neotropical streams. Fundam Appl Limnol. 2012; 181(2):12942. http://dx.doi.org/10.1127/1863-9135/2012/0242

Marrero C, Winemiller KO. Tube-snouted gymnotiform and mormyriform fishes: Convergence of a specialized foraging mode in teleosts. Environ Biol Fishes. 1993; 38(4):299-309.

Mojica JI, Castellanos C, Lobón-Cerviá J. High temporal species turnover enhances the complexity of fish assemblages in Amazonian Terra firme streams. Ecol of Freshw Fish. 2009; 18(4):520-26. https://doi.org/10.1111/j.1600-0633.2009.00382.x

Mojica JI, Galvis G, Arbeláez F, Santos M, Vejarano S, PrietoPiraquive E, Arce M, Sánchez-Duarte P, Castellanos C, Gutiérrez A, Duque SR, Lobón-Cerviá J, Granado-Lorencio C. Peces de la cuenca del río Amazonas en Colombia: región de Leticia. Biota Colomb. 2005; 6(2):191-210.

Mojica JI, Lobón-Cerviá J, Castellanos C. Quantifying fish species richness and abundance in Amazonian streams: Assessment of a multiple year method suitable for terra firme stream fish assemblages. Fish Manag and Ecol. 2014; 21(3):220-33. https://doi.org/10.1111/fme.12067

Moller P. Electric signals and schooling behavior in a weakly electric fish, Marcusenius cyprinoides L. (Mormyriformes). Science. 1976; 193(4254):697-99. http://dx.doi.org/10.1126/ science. 948747

Moller P. Multimodal sensory integration in weakly electric fish: A behavioral account. J Physiol (Paris). 2002; 96(5-6):547-56. https://doi.org/10.1016/S0928-4257(03)00010-X

Ramirez F, Davenport TL, Mojica JI. Dietary-morphological relationships of nineteen fish species from an Amazonian terra firme blackwater stream in Colombia. Limnologica. 2015; 52:89-102.

Rasband WS. ImageJ. National Institutes of Health, Bethesda, Maryland, USA. 2019. [Internet] http://imagej.nih.gov/ij.

Rodriguez MA. Restricted movement in stream fish: the paradigm is incomplete, not lost. Ecology. 2002; 83(1):1-13. http:// dx.doi.org/10.2307/2680115

Rueda-Delgado G, Wantzen KM, Tolosa MB. Leaf-litter decomposition in an Amazonian floodplain stream: Effects of seasonal hydrological changes. J North Am Benthol Soc. 2006; 25(1):233-49. https://doi.org/10.1899/0887-3593

Schwassmann HO. Ecology and taxonomic status of different geographic populations of Gymnorhamphichthys hypostomus Ellis (Pisces, Cypriniformes, Gymnotiodei). Biotropica. 1976; $8(1): 25-40$ 
Silva A, Perrone R, Macadar O. Environmental, seasonal, and social modulations of basal activity in a weakly electric fish. Physiol Behav. 2007; 90(2-3):525-36. https://doi.org/10.1016/j. physbeh.2006.11.003

Silvano RAM, Amaral BD, Oyakawa OT. Spatial and temporal patterns of diversity and distribution of the upper Jurua River fish community (Brazilian Amazon). Environ Biol Fishes. 2000; 57(1):25-35. https://doi.org/10.1023/A:1007594510110

Squire A, Moller P. Effects of water conductivity on electrocommunication in the weak-electric fish Brienonyrus niger (Mormyriformes). Anim Behav. 1982; 30(2):375-82.

Thomas M, Florion M, Chrétien D. The effect of $\mathrm{pH}$ and conductivity on the electric behaviour of Apteronotus albifrons (Family Apteronotidae) in a pollution monitoring system. Environ Technol. 1997; 18(11):1069-83. https://doi. org/10.1080/09593331808616627
Westby GWM. The ecology, discharge diversity and predatory behavior of gymnotiforme electric fish in the coastal streams of French Guiana. Behav Ecol Sociobiol. 1988; 22(5):341-54. https://doi.org/10.1007/BF00295103

Zuanon J, Bockmann FA, Sazima I. A remarkable sand-dwelling fish assemblage from central Amazonia, with comments on the evolution of psammophily in South American freshwater fishes. Neotrop Ichthyol. 2006; 4(1):107-18. http://dx.doi. org/10.1590/S1679-62252006000100012

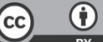

Submitted in January 24, 2019 Accepted in September 13, 2019 by Willian Crampton 